\title{
PROTOPLAST ISOLATION FROM SHOOTS OF ASPARAGUS CULTURES
}

\author{
CHEN GUANGYU,,+ A. J. CONNER, ${ }^{1, *}, \dagger$ M. C. CHRISTEY,* A. G. FAUTRIER, $\dagger$ AND R. J. FIELD $\dagger$ \\ *New Zealand Institute for Crop \& Food Research Ltd., Private Bag 4704, Christchurch, New Zealand; and \\ $\dagger$ Department of Plant Science, P. O. Box 84, Lincoln University, Canterbury, New Zealand
}

\begin{abstract}
Experiments to maximize the isolation and purification of viable protoplasts from shoot cultures of asparagus (Asparagus officinalis L.) were conducted. Important factors for high yield of viable protoplasts included: the use of in vitro etiolated shoots as source material; $0.6 \mathrm{M}$ glucose as an osmoticum in a modified $\mathrm{KM}$ medium; a combination of pectinase, cellulase, and hemicellulase, each at $1 \%(\mathrm{w} / \mathrm{v})$ for enzymatic digestion of cell walls; and physical factors such as the volume of enzyme solution and speed of gyratory shaking. Protoplasts were purified by suspending digested etiolated shoot tissue in $0.6 \mathrm{M}$ sucrose, overlaid with KMG medium and centrifugation at $650 \mathrm{~g}$. The asparagus genotype had a marked influence on protoplast yield, with some genotypes yielding up to $18.4 \times 10^{6}$ protoplasts/g fresh etiolated shoot tissue with $90 \%$ viability.
\end{abstract}

\section{Introduction}

Efficient procedures for the isolation, culture, and regeneration of asparagus (Asparagus officinalis L.) protoplasts are important for the genetic manipulation of asparagus by cellular and molecular techniques. Previous reports on asparagus protoplast isolation have used callus or cell suspensions as the source tissue (Kong and Chin 1988; Elmer et al. 1989; Hsu et al. 1990; Kunitake and Mii 1990; Dan and Stephens 1991; May and Sink 1995). Such source tissues have the disadvantages of reduced regeneration ability and/or the gradual accumulation of genetic changes during prolonged culture (Lee and Phillips 1988; Conner and Meredith 1989). Genetic instability has been associated with callus culture of asparagus (Malnassy and Ellison 1970; Hirate et al. 1995; Kunitake 1995); therefore, the use of shoot tissue as the source material offers an important solution to minimize such problems. Bui-Dang-Ha and Mackenzie (1973) used cladodes as the source, but the yield of protoplasts was not presented and presumed to be low. There is no report of using shoots of in vitro asparagus cultures for protoplast isolation and culture. In a large number of other plant species, shoot cultures have been shown to be an excellent source for high and reproducible yields of protoplasts (Eriksson 1985).

The objectives of this study were to maximize the protoplast yield from in vitro asparagus shoots by investigating the effect of enzyme combinations, volume of enzyme solution, speed of gyratory shaking, genotype differences, and types of source tissue.

\section{Material and methods}

\section{ASPARAGUS GENOTYPES}

The asparagus genotypes used were all micropropagated clones under evaluation as parents of hybrid cultivars and included four male clones: CRD 67, CRD 70 (both ex Mary

\footnotetext{
'Author for correspondence and reprints; fax +64 3 3252074; E-mail connert@crop.cri.nz.
}

Manuscript received September 1996; revised manuscript received April 1997.
Washington 500), CRD 126 (ex New Jersey 101) and CRD 157 (ex Larac); and three female clones: CRD 74, CRD 75 (both ex Mary Washington 500), and CRD 168 (ex Limbras I).

\section{CUlture initiation}

In vitro plant cultures with roots were established as described by Abernethy and Conner (1992) and grown for six weeks on MS salts and vitamins (Murashige and Skoog 1962), supplemented with $400 \mathrm{mg} / \mathrm{L}$ glutamine, $30 \mathrm{~g} / \mathrm{L}$ sucrose, and $7 \mathrm{~g} / \mathrm{L}$ agar. Cultures were incubated at $27^{\circ} \mathrm{C}$ under cool white fluorescent lamps $\left(100 \mu \mathrm{mol} \mathrm{m}^{-2} \mathrm{~s}^{-1} ; 16 \mathrm{~h}\right.$ light : $8 \mathrm{~h}$ dark photoperiod) for production of green shoots or in darkness for production of etiolated shoots.

\section{ENZYME MIXTURES}

Different combinations of pectinase (NBS Biologicals 01-14443/8), cellulase (Onozuka R-10 Yakult Honsha Co., Ltd.), and hemicellulase (Sigma H-2125) were used for tissue digestion. Combinations of two enzymes (pectinase and cellulase) or three enzymes (pectinase, cellulase, and hemicellulase) at concentrations of $1 \%$ and $2 \%(\mathrm{w} / \mathrm{v})$ were tested. They were dissolved in KM medium as described by Elmer et al. (1989), except modified by eliminating sucrose and including $3 \mathrm{mM}$ MES, an additional $7 \mathrm{mM} \mathrm{CaCl}_{2}$, and either $0.6 \mathrm{M}$ mannitol as an osmoticum (without glucose), or with $0.6 \mathrm{M}$ glucose (without mannitol). Enzyme solutions were filter sterilized (Minisart $0.20 \mu \mathrm{m}$, Sartorius) before use.

\section{PROTOPLAST ISOLATION AND PURIFICATION}

In vitro asparagus shoots were sliced into pieces ca. $1 \mathrm{~mm}$ long. In each experiment, $0.8-1 \mathrm{~g}$ of freshly sliced shoots were used for each of three replications. They were transferred to petri dishes $(8.5 \mathrm{~cm}$ diam $\times 1.2 \mathrm{~cm}$ high), submerged in $10 \mathrm{~mL}$ or $20 \mathrm{~mL}$ of the enzyme mixture, sealed with Parafilm, and placed on a gyratory shaker (Mistral Multi-Mixer, Lab-Line Instrument) with $0.5 \mathrm{~cm}$ diam orbits and at $60 \mathrm{rpm}$, gentle agitation, or $200 \mathrm{rpm}$, vigorous agitation. After $20 \mathrm{~h}$, the digested tissue was passed through $80-\mu \mathrm{m}$ diam nylon mesh, and centrifuged at room temperature in swinging buckets for $10 \mathrm{~min}$ at $500 \mathrm{~g}$ or $650 \mathrm{~g}$. The pellet was resuspended in $7 \mathrm{~mL}$ of autoclaved sucrose solution $(0.32 \mathrm{M}-0.6 \mathrm{M})$, then $2 \mathrm{~mL}$ of autoclaved $0.6 \mathrm{M}$ glucose, or KMG medium (KM medium as described by Elmer et al. [1989] without mannitol and with $0.6 \mathrm{M}$ glucose) was carefully overlaid on the sucrose solution. After centrifugation at $500 \mathrm{~g}$ or $650 \mathrm{~g}$ for $10 \mathrm{~min}$, the interface was carefully 
removed, transferred to another centrifuge tube, and recentrifuged at $500 \mathrm{~g}$ or $650 \mathrm{~g}$ for $10 \mathrm{~min}$. The pellet was washed with $2 \mathrm{~mL}$ of $\mathrm{KMG}$ medium and centrifuged at $500 \mathrm{~g}$ or $650 \mathrm{~g}$ for $10 \mathrm{~min}$. Finally, the pellet was resuspended in 1 $\mathrm{mL}$ of KMG medium.

\section{MICROSCOPY AND PROTOPLAST VIABILITY}

Protoplasts were counted with a hemacytometer and viability, defined as the percentage of viable protoplasts, was assessed with fluorescein diacetate (FDA; Widholm 1972).

\section{IMAGE ANALYSIS FOR PROTOPLAST SIZE}

The size of freshly isolated protoplasts was measured by image analysis using the Video Pro 32 package (Leading Edge Pty. Ltd., 1A Downing St., Hove, Adelaide, S.A., Australia) according to Coles et al. (1991). An inverted microscope was connected to a color surveillance camera and the system was calibrated using a graticule with $0.01 \mathrm{~mm}$ graduations, to convert pixel into $\mu \mathrm{m}$. Measurements were made on 100 randomly selected protoplasts suspended in KMG medium.

\section{DATA ANALYSIS}

Minitab package (version 10.1), Quattro Pro (version 5), and WordPerfect Presentation (version 2.0) were used for statistical analysis and graphics. The data for protoplast viability were angular transformed for statistical analysis when necessary (angle $=\arcsin (\%)^{0.5}$; Snedecor and Cochran 1969).

\section{Results}

\section{ENZYMATIC RELEASE OF PROTOPLASTS}

Cellulase and pectinase were investigated at all combinations of $1 \%$ and $2 \%(\mathrm{w} / \mathrm{v})$ with $0.6 \mathrm{M}$ mannitol as osmoticum on green asparagus shoots. Three experiments indicated that genotypes CRD 67, CRD 126 , and CRD 168 yielded more protoplasts than CRD 70, CRD 74, and CRD 75, but all combinations had low yields $\left(<10^{4}\right.$ protoplasts/g shoot tissue). Subsequently, $0.5 \%, 1 \%$, and $2 \%(\mathrm{w} / \mathrm{v})$ cellulase and hemicellulase were tested in combination with $1 \%(\mathrm{w} / \mathrm{v})$ pectinase using mannitol as osmoticum. A total of 11 experiments using both green and etiolated shoots of genotypes CRD 67, CRD 70, CRD 74, CRD 75, CRD 126 , and CRD 168 established that the best combination of these three enzymes was $1 \%(\mathrm{w} / \mathrm{v})$ each of pectinase, cellulase, and hemicellulase for etiolated shoots, and $1 \%$ pectinase, $2 \%$ cellulase, and $2 \%$ hemicellulase for green shoots. These combinations, respectively, were used in all subsequent experiments.

\section{Centrifugation and SUCROSE CONCENTRATION}

Enzyme-digested shoot tissues were resuspended in a range of sucrose concentrations, $0.32 \mathrm{M}$ to $0.6 \mathrm{M}$, overlaid with $0.6 \mathrm{M}$ glucose and centrifuged at $500 \mathrm{~g}$ or $650 \mathrm{~g}$. After centrifugation, the band of purified protoplasts accumulated at the interface; whereas, cellular debris was pelleted. Centrifugation at both $500 \mathrm{~g}$ and $650 \mathrm{~g}$ effectively separated protoplasts from debris, but $650 \mathrm{~g}$ produced a higher protoplast yield. Sucrose at $0.55 \mathrm{M}$ and $0.6 \mathrm{M}$ were selected for the band-

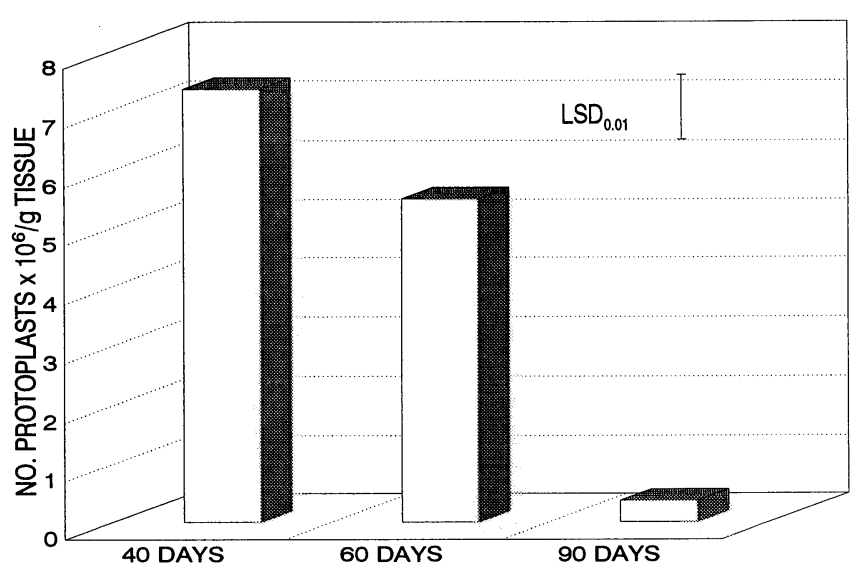

Fig. 1 Protoplast yield from etiolated shoot cultures of CRD 67 at $40 \mathrm{~d}, 60 \mathrm{~d}$, and $90 \mathrm{~d}$ after the last subculture.

ing of protoplasts from green and etiolated shoots, respectively, because larger protoplast bands were observed at these concentrations compared to other sucrose concentrations.

\section{AGE OF DONOR SHOOT CULTURES}

To test the effect of age of plant cultures or the time interval between subcultures on protoplast yield, protoplasts were isolated from etiolated shoot cultures of CRD 67 aged $40 \mathrm{~d}, 60 \mathrm{~d}$, and $90 \mathrm{~d}$ since the last subculture. Analysis of variance established a significant difference between age of source tissue $(P<0.001)$ with younger cultures yielding more protoplasts than older cultures (fig. 1). The viability of harvested protoplasts also decreased drastically with increasing age of donor cultures (data not shown). Experiments with CRD 126 and CRD 168 determined that protoplasts could be released from shoot cultures in a wide range of ages from $3 \mathrm{wk}$ to $3 \mathrm{mo}$ and confirmed that protoplast yield declined rapidly with culture age. Since donor cultures aged less than 4 wk did not usually produce sufficient shoot material, cultures aged ca. 40 $\mathrm{d}$ were used in subsequent experiments.

\section{EVALUATION OF MEDIA}

Freshly isolated protoplasts from etiolated shoots of CRD 67 were cultured in six media commonly used for asparagus and viability was monitored over the next $10 \mathrm{~d}$. Analysis of variance of data from four independent protoplast isolations established a significant difference among the media on days 3,6 , and 10 $(P<0.001$ for all time points), with protoplast viability decreasing over time, especially during the first $3 \mathrm{~d}$ (fig. 2). Protoplasts cultured in KM medium maintained a substantially higher viability during the 10-d period (fig. 2). Therefore, KM medium was used as a base in all subsequent experiments for protoplast isolations.

\section{GLUCOSE OR MANNITOL AS OSMOTICUM}

Three independent isolations of protoplasts from etiolated shoots (two for CRD 67 and one for CRD 70) 


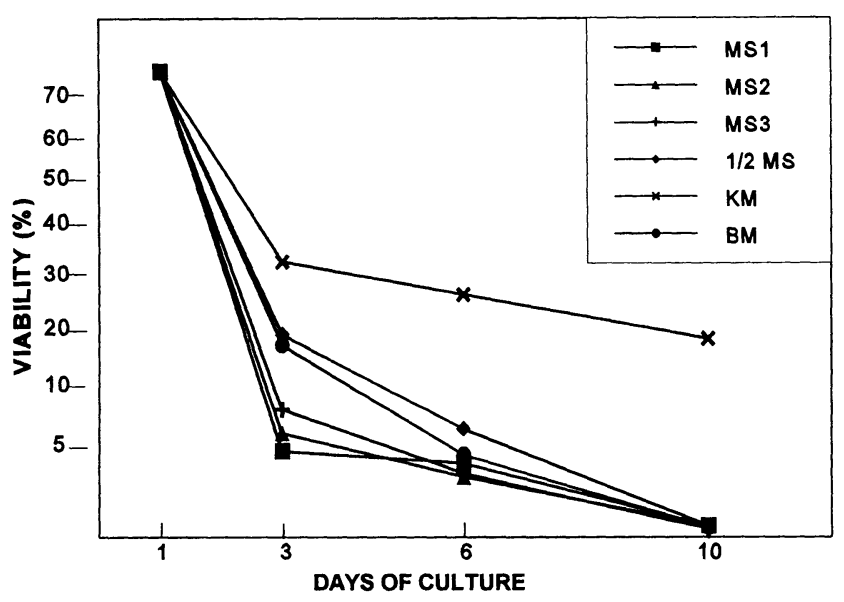

Fig. 2 Viability of protoplasts from etiolated shoots of asparagus genotype CRD 67 in six different media. Following isolation with mannitol as osmoticum, protoplasts were cultured in six different liquid media: MS1 (Chin et al. 1988); MS2 (Kunitake and Mii 1990); MS3 (Dan and Stephens 1991); 1/2MS (Kunitake and Mii 1990); KM (Elmer et al. 1989); BM (Bui-Dang-Ha and Mackenzie 1973). The actual percent viability is superimposed on the angular transformed scale, with the $\mathrm{LSD}_{0.01}$ being $12.1 \%, 7.7 \%$, and $3.5 \%$ for day 3 , day 6 , and day 10 , respectively.

were used to compare glucose and mannitol as osmotica. Although the magnitude of the viability varied between experiments, the trend was the same for all experiments. For each isolation, analysis of variance established that glucose as an osmoticum yielded significantly higher protoplast viability than mannitol ( $P$ $<0.05$; fig. 3). Glucose was therefore used as an osmoticum for enzyme digestion and protoplast purification in all following experiments.

\section{PHYSICAL PARAMETERS AND PROTOPLAST YIELD}

The effect of physical factors such as speed of shaking during enzymatic digestion and volume of enzyme solution on protoplast yield were investigated for green and etiolated shoot cultures from three genotypes. Treatments involved all four combinations of two enzyme volumes $(10 \mathrm{~mL}$ and $20 \mathrm{~mL})$ and two speeds of gyratory shaking (60 rpm and $200 \mathrm{rpm}$ ). Although protoplast yield varied with genotype, increase in the speed of shaking from $60 \mathrm{rpm}$ to 200 rpm was accompanied with higher protoplast yields for both green and etiolated tissue (fig. 4). Protoplast yield increased significantly when the volume of enzyme solution was doubled from $10 \mathrm{~mL}$ to $20 \mathrm{~mL}$. This effect was apparent for each genotype at either lower speed or at higher speed, although the magnitudes of the differences varied between the genotypes (figs. 4, 5). With the conventional regime $(10 \mathrm{~mL}$ of enzyme solution combined with $60 \mathrm{rpm}$ of shaking speed), doubling the concentration of the three enzymes (pectinase, cellulase, and hemicellulase) from $1 \%$ to $2 \%$ of each (w/v), without increasing the volume of enzyme solution did not cause a proportional increase in protoplast yield of genotype CRD 67. The yield from these two treatments was not significantly different

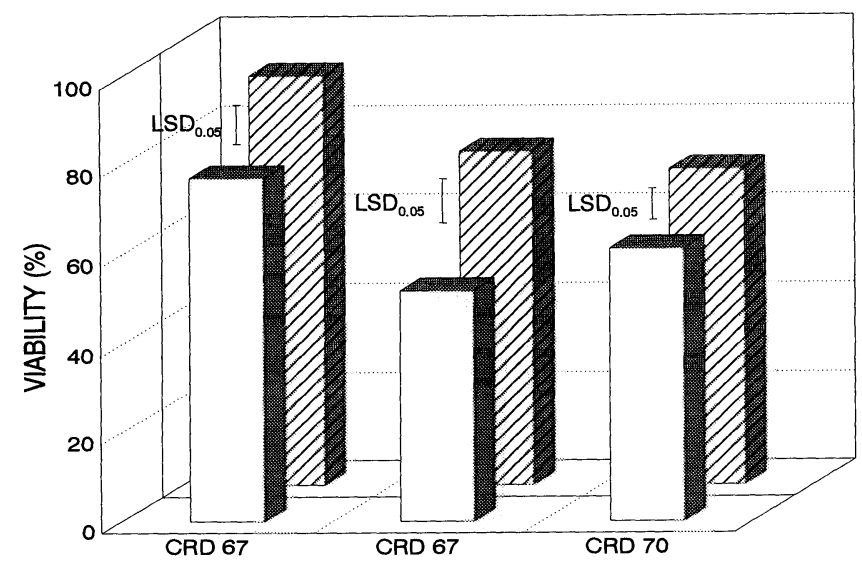

Fig. 3 Protoplast viability of genotypes CRD 67 and CRD 70 with either mannitol (front bar) or glucose (back bar) as an osmoticum.

$\left(\right.$ means $=2.77 \times 10^{6}$ and $3.02 \times 10^{6}$ protoplasts $/ g$ fresh tissue; $\mathrm{SE}=0.22 \times 10^{6}$ ).

\section{GREEN OR ETIOLATED SHOOT TISSUE}

Etiolated shoots yielded more protoplasts than green shoots, even when the optimized enzyme combination of $1 \%$ pectinase, $1 \%$ cellulase, and $1 \%$ hemicellulase was used for etiolated shoots and $1 \%$ pectinase, $2 \%$ cellulase, and $2 \%$ hemicellulase was used for green shoots. This was evident for all the tested combinations of volume of the enzyme solution and gyratory shaker speed during isolation (fig. 4).

\section{GENOTYPE RESPONSE}

The asparagus genotype had a marked effect on the yield of protoplasts (figs. 4, 5). CRD 67 and CRD 168 were more amenable to enzyme digestion, whereas CRD 70, CRD 74, CRD 75, and CRD 126 gave low yields of protoplasts. For example, the protoplast yield from shoot cultures of CRD 67 and CRD 168 were generally twice that of CRD 75 (fig. 4).

\section{SIZE AND VIABILITY OF FRESH PROTOPLASTS}

The freshly isolated protoplasts from etiolated shoots were quite uniform in size. All genotypes had a similar size ranging from $11.6 \pm 0.5 \mu \mathrm{m}$ (CRD 74) to $13.4 \pm 0.5$ (CRD 126) $\mu \mathrm{m}$. The average viability of these protoplasts in KMG medium was $90.5 \% \pm$ 4.8 , with identical results for all genotypes.

\section{Discussion}

This study is the first report of successful isolation and purification of asparagus protoplasts from shoots of in vitro cultures. The recommended protocol is summarized in table 1. Protoplast yields of up to 18.4 $\times 10^{6}$ protoplasts/g fresh etiolated shoots with $90 \%$ viability can be routinely achieved with this protocol.

Varying combinations of pectinase and cellulase did not give good protoplast yields from asparagus shoot cultures, indicating that these two enzymes were insufficient for complete digestion of cell walls of asparagus shoots. Asparagus shoots contain a range of 

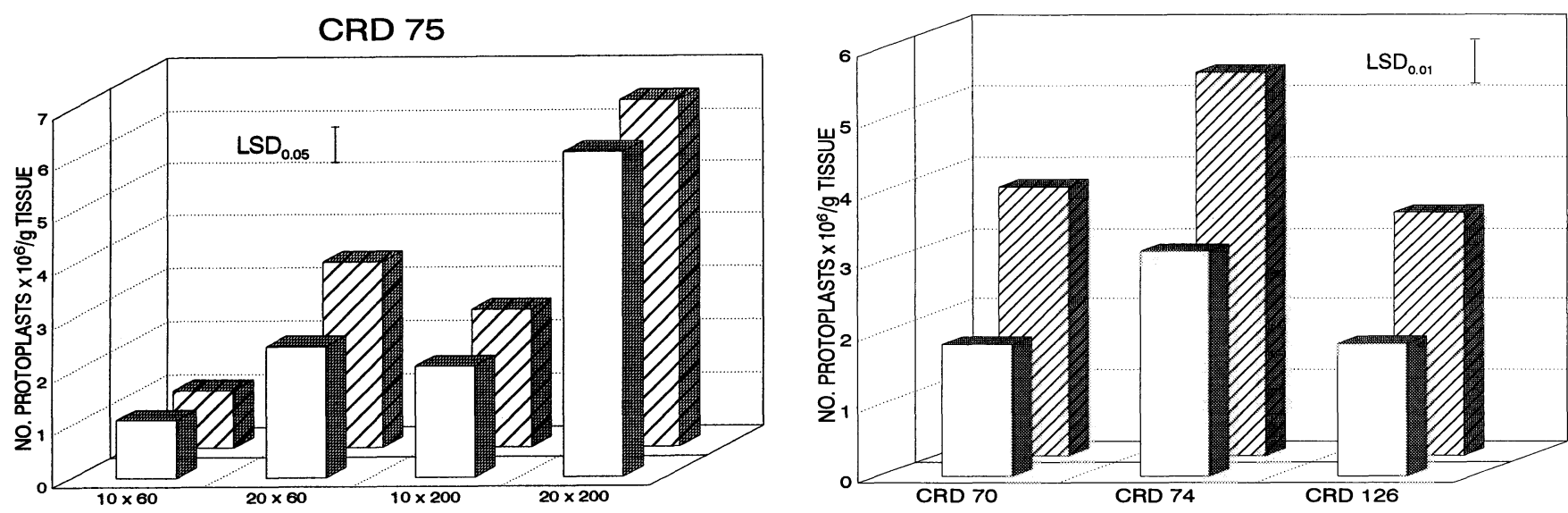

Fig. 5 Influence of volume of enzyme solution on protoplast yield from etiolated shoot cultures of three asparagus genotypes. Gyratory shaking was $60 \mathrm{rpm}$ with volume of enzyme at $10 \mathrm{~mL}$ (front bar) or $20 \mathrm{~mL}$ (back bar). Analysis of variance established a significant difference between the two volumes and between genotypes (both $P<0.001)$ with no significant interaction.

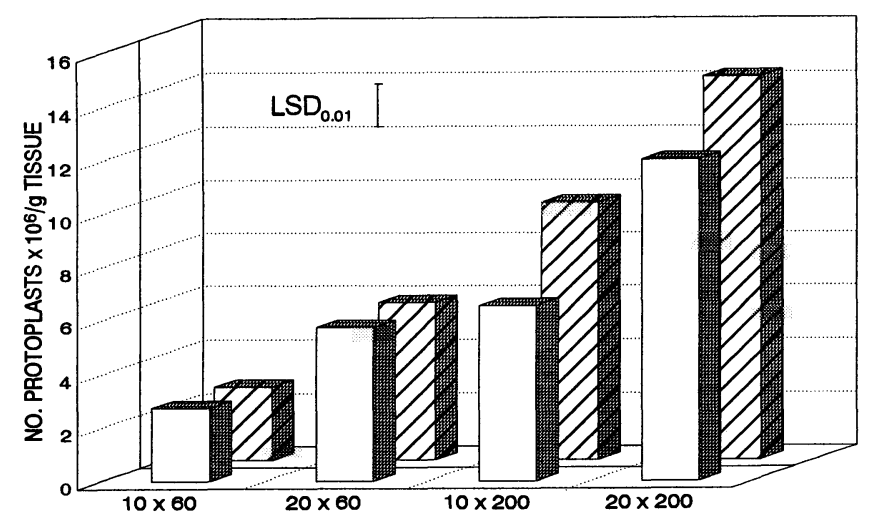

cell types, which differ markedly in their cell wall composition (Waldron and Selvendran 1990a). The overall composition of the component polysaccharides of the cell wall are cellulose and pectic polysaccha-

\section{Table 1}

PROTOCOL FOR ISOLATION OF PROTOPLASTS FROM SHOOTS OF IN VITRO ASPARAGUS CULTURES

1. Incubate cultures of asparagus plants at $27^{\circ} \mathrm{C}$ in darkness for ca. $6 \mathrm{wk}$.

2. Aseptically chop etiolated shoots into ca. 1-mm segments.

3. Place $1 \mathrm{~g}$ of freshly chopped tissue into a petri dish $(85 \mathrm{~mm}$ diam $\times 12 \mathrm{~mm}$ high), add $20 \mathrm{~mL}$ of filter sterilized enzyme solution $(1 \%$ pectinase, $1 \%$ cellulase, and $1 \%$ hemicellulase in KM medium as described by Elmer et al. [1989], without mannitol or sucrose, but with $3 \mathrm{mM} \mathrm{MES}$, an additional $7 \mathrm{mM} \mathrm{CaCl}_{2}$ and glucose increased to $0.6 \mathrm{M}$ ).

4. Seal petri dish with Parafilm and place on a gyratory shaker at $200 \mathrm{rpm}$ for $20 \mathrm{~h}$

5. Filter digested tissue through an $80-\mu$ m nylon mesh.

6. Centrifuge at room temperature in swinging buckets for $10 \mathrm{~min}$ at $650 \mathrm{~g}$.

7. Discard the supernatant. Resuspend the pellet in $7 \mathrm{~mL}$ of $0.6 \mathrm{M}$ sucrose solution.

8. Carefully add $2 \mathrm{~mL}$ of $\mathrm{KMG}$ medium (KM medium as described by Elmer et al. [1989], but without mannitol and with glucose increased to $0.6 \mathrm{M}$ ), so that it floats on top of the protoplasts suspended in sucrose solution.

9. Centrifuge at $650 \mathrm{~g}$ for $10 \mathrm{~min}$. The protoplasts float to the interface of the sucrose solution and the KMG medium, while cellular debris pellets at the bottom of the tube.

10. Carefully remove the protoplasts from the interface using a 1$\mathrm{mL}$ pipette (avoid taking the sucrose solution, the bottom layer). Resuspend protoplasts in $5 \mathrm{~mL}$ of KMG medium.

11. Determine the concentration of protoplasts using a hamocytometer.

12. Centrifuge at $650 \mathrm{~g}$ for $10 \mathrm{~min}$ to pellet the protoplasts.

13. Discard the supernatant. Resuspend the protoplasts in KMG medium at the desired concentration for experiments.

significant effects of volume $\times$ speed $(P<0.01)$ and speed $\times$ source tissue $(P<0.001)$. For CRD 168 main effect and all interactions were highly significant (all $P<0.001$, except for volume $\times$ speed at $P<0.01$ ).

Note. For protoplasts from in vitro green shoots, the enzyme solution should contain $1 \%$ pectinase, $2 \%$ cellulase, and $2 \%$ hemicellulase, and a $0.55 \mathrm{M}$ sucrose solution should be used for density gradient centrifugation to purify protoplasts. 
rides, as well as larger amounts of xylose and glucosecontaining (hemicellulosic) polysaccharides (Waldron and Selvendran $1990 \mathrm{~b} ; 1992)$. Therefore, addition of hemicellulase to the enzyme mixture was essential for sufficient release of protoplasts from asparagus shoot tissue as previously observed when using asparagus suspension cells as a tissue source (Hsu et al. 1990). This requirement for hemicellulase may account for the low protoplast yields reported in many studies that used only cellulase and pectinase (Bui-Dang-Ha and Mackenzie 1973; Chin et al. 1988; Kong and Chin 1988; Kunitake and Mii 1990).

Centrifugation procedures previously described for purification of protoplasts from asparagus callus (Kong and Chin 1988; Elmer et al. 1989; Kunitake and Mii 1990; Dan and Stephens 1991) failed to harvest protoplasts from asparagus shoot cultures. A higher sucrose concentration and centrifugation at $650 \mathrm{~g}$ were necessary to separate protoplasts from the shoot debris. This was probably related to the protoplasts originating from a different tissue with a different size or mass that conferred different sedimentation rates and buoyant density. Protoplasts from shoot cultures in this study were quite uniform in size and ranged from 11.6 to $13.4 \mu \mathrm{m}$ diam. This was smaller than those reported from callus tissue $(20 \mu \mathrm{m}$ in diam, Kunitake and Mii 1990; 15-30 $\mu \mathrm{m}$, Elmer et al. 1989) or from cladodes (15-30 $\mu \mathrm{m}$ in diam, Bui-Dang-Ha and Mackenzie 1973). The purification of protoplasts from green asparagus shoots required a lower concentration of sucrose $(0.55 \mathrm{M})$ than etiolated shoots $(0.6 \mathrm{M}$ sucrose $)$ for density gradient centrifugation. This may be a consequence of the difference in protoplast density resulting from the presence of etioplasts in etiolated tissue and chloroplasts in green tissue.

The age of the source plants was critical for successful protoplast isolation (fig. 1). The use of shoot tissue from older cultures resulted in poor protoplast yields, which may result from the older cultures having greater secondary cell wall formation. Etiolated shoots consistently yielded more protoplasts than green shoots (fig. 4), which may result from etiolated cells having a different cell wall structure. From the observation that it required the same amount of pectinase, but twice as much cellulase and hemicellulase to digest green shoots than etiolated shoots, we deduced that the green shoots have accumulated thicker secondary cell walls.

Mannitol and sorbitol are used more often than glucose as an osmoticum during protoplast isolation because they are considered to be relatively inert metabolically, and they infuse slowly into the protoplasts. However, a combination of inert and metabolically active osmotic stabilizers was suggested to be of some advantage for protoplast isolation ( $\mathrm{Lu}$ et al. 1981). Protoplasts isolated from asparagus callus with glucose as the osmoticum grew much faster than when mannitol or sorbitol were used (Kong and Chin 1988). Results from this study confirmed the advantage of using glucose as an osmoticum for asparagus protoplast isolation (fig. 3). Highest viability was achieved using a modified KM medium containing $0.6 \mathrm{M}$ glucose for protoplasts isolated from both green and etiolated shoots of in vitro asparagus cultures.

Higher protoplast yield at $200 \mathrm{rpm}$ (fig. 4) helped the release of protoplasts via either the mechanical force of agitation helping to separate the plasmolyzed cells and/or the movement of the solution maintaining a uniform concentration of cell wall degrading enzymes. However, at $300 \mathrm{rpm}$, most protoplasts burst, resulting in a very low protoplast yield. Poor protoplast yield resulting from high speed agitation has been previously demonstrated in maize (Imbrie-Milligan and Hodges 1986).

The relationship between volume of enzyme solution and quantitative release of protoplasts may result from insufficient enzyme per volume in $10 \mathrm{~mL}$ of solution for complete digestion. Doubling the enzyme concentration without increasing the volume did not cause a proportional increase in protoplast yield. Therefore, we deduced higher protoplast yields when using $20 \mathrm{~mL}$ of enzyme solution was related to the dynamics of agitation and the greater physical space in the solution for the plant tissue to interact with the enzyme.

Most studies on asparagus protoplast isolation have used only single genotypes (Bui-Dang-Ha and Mackenzie 1973; Chin et al. 1988; Kong and Chin 1988; Hsu et al. 1990; Kunitake and Mii 1990; Dan and Stephens 1991). Although no differences were noted between genotypes when using callus as a source tissue (Elmer et al. 1989), genotypic differences in the efficiency of protoplast isolation were reported for embryogenic cell suspensions (May and Sink 1995). Marked genotypic differences were also observed when using both etiolated and green shoot cultures of asparagus for protoplast isolation (figs. 4, 5). This establishes the importance of identifying appropriate genotypes when using protoplasts for the genetic manipulation of asparagus.

\section{Acknowledgments}

We thank Andrew Wallace for advice on statistical analysis and Dr. Peter Falloon for providing the initial plant material. This work was supported by a Lincoln University doctoral scholarship to Chen Guangyu and the New Zealand Institute for Crop \& Food Research Ltd.

\section{Literafure cited}

Abernethy DJ, AJ Conner 1992 Laboratory guide for the micropropagation of asparagus. Crop \& Food Research Report, no.1. Christchurch, New Zealand.
Bui-Dang-Ha D, IA Mackenzie 1973 The division of protoplasts from Asparagus officinalis $\mathrm{L}$. and their growth and differentiation. Protoplasma 78:215-221. 
Chin CK, Y Kong, H Pedersen 1988 Culture of droplets containing asparagus cells and protoplasts on polypropylene membrane. Plant Cell Tissue Organ Cult 15:59-65.

Coles GD, DJ Abernethy, MC Christey, AJ Conner, BK Sinclair 1991 Monitoring hairy-root growth by image analysis. Plant Mol Biol 9:13-20.

Conner AJ, CP Meredith 1989 Genetic manipulation of plant cells. Pages 653-688 in A Marcus, ed. The biochemistry of plants, a comprehensive treatise. Vol 15. Molecular biology. Academic Press, Orlando, Fla.

Dan YH, CT Stephens 1991 Studies of protoplast culture types and plant regeneration from callus-derived protoplasts of Asparagus officinalis L. cv. Lucullus 234. Plant Cell Tissue Organ Cult 27: 321-331.

Elmer WH, T Ball, M Volokita, CT Stephens, KC Sink 1989 Plant regeneration from callus-derived protoplasts of asparagus. J Am Soc Hortic Sci 114:1019-1024.

Eriksson TR 1985 Protoplast isolation and culture. Pages 1-20 in LC Fowke, F Constabel, eds. Plant protoplasts. CRC Press, Boca Raton, Fla.

Hirate Y, H Araki, T Harada 1995 Image processing of asparagus chromosomes. Asparagus Res Newsletter 12:42-43.

Hsu JY, CC Yeh, TP Yang, WC Lin, HS Tsay 1990 Initiation of cell suspension cultures and plant regeneration from protoplast of asparagus. Acta Hortic 271:135-143.

Imbrie-Milligan CW, TK Hodges 1986 Microcallus formation from maize protoplasts prepared from embryogenic callus. Planta 168: 395-401.

Kong Y, CK Chin 1988 Culture of asparagus protoplasts on porous polypropylene membrane. Plant Cell Rep 7:67-69.
Kunitake I 1995 Chromosome variation of somatic embryo-derived plants of haploid asparagus. Asparagus Res Newsletter 12:45-46.

Kunitake H, M Mii 1990 Somatic embryogenesis and plant regeneration from protoplasts of asparagus (Asparagus officinalis L.). Plant Cell Rep 8:706-710.

Lee M, RL Phillips 1988 The chromosomal basis of somaclonal variation. Annu Rev Plant Physiol Plant Mol Biol 39:413-438.

Lu CY, V Vasil, IK Vasil 1981 Isolation and culture of protoplasts of Panicum maximum Jacq. (Guinea Grass)—somatic embryogenesis and plantlet formation. Z Pflanzenphysiol 104:311-318.

Malnassy P, JH Ellison 1970 Asparagus tetraploids from callus tissue. Hortscience 5:444-445.

May RA, Sink KC 1995 Genotype and auxin influence direct somatic embryogenesis from protoplasts derived from embryogenic cell suspensions of Asparagus officinalis L. Plant Science 108:7184.

Murashige T, F Skoog 1962 A revised medium for rapid growth and bioassays with tobacco tissue cultures. Physiol Plant 15:473497.

Snedecor GW, WG Cochran 1969 Statistical methods. 6th ed. Iowa State University Press, Ames. 593 pp.

Waldron KW, RR Selvendran $1990 a$ Composition of the cell walls of different asparagus (Asparagus officinalis) tissues. Physiol Plant 80:568-575.

$1990 \mathrm{~b}$ Effect of maturation and storage on asparagus (As paragus officinalis) cell wall composition. Physiol Plant 80:576583.

1992 Cell wall changes in immature Asparagus stem tissue after excision. Phytochemistry 31:1931-1940.

Widholm JM 1972 The use of fluorescein diacetate and phenosafranine for determining viability of cultured plant cells. Stain Technol 47:189-194. 